\title{
Progress Toward Development of Effective and Safe African Swine Fever Virus Vaccines
}

\author{
Huldah Sang ${ }^{1 \dagger}$, Gabrielle Miller ${ }^{1 \dagger}$, Shehnaz Lokhandwala ${ }^{1}$, Neha Sangewar ${ }^{1}$, \\ Suryakant D. Waghela ${ }^{2}$, Richard P. Bishop ${ }^{3}$ and Waithaka Mwangi ${ }^{1 *}$
}

1 Department of Diagnostic Medicine/Pathobiology, Kansas State University, Manhattan, KS, United States, ${ }^{2}$ Department of Veterinary Pathobiology, Texas A\&M University, College Station, TX, United States, ${ }^{3}$ Department of Veterinary Microbiology and Pathology, Washington State University, Pullman, WA, United States

African swine fever is a major concern due to its negative impact on pork production in affected regions. Due to lack of treatment and a safe vaccine, it has been extremely difficult to control this devastating disease. The mechanisms of virus entry, replication within the host cells, immune evasion mechanisms, correlates of protection, and antigens that are effective at inducing host immune response, are now gradually being identified. This information is required for rational design of novel disease control strategies. Pigs which recover from infection with less virulent ASFV isolates can be protected from challenge with related virulent isolates. This strongly indicates that an effective vaccine against ASFV could be developed. Nonetheless, it is clear that effective immunity depends on both antibody and cellular immune responses. This review paper summarizes the key studies that have evaluated three major approaches for development of African Swine Fever virus vaccines. Recent immunization strategies have involved development and in vivo evaluation of live attenuated virus, and recombinant protein- and DNA-based and virus-vectored subunit vaccine candidates. The limitations of challenge models for evaluating ASFV vaccine candidates are also discussed.

Keywords: ASF, vaccine, attenuated virus, subunit vaccine, live vector

\section{INTRODUCTION}

African swine fever is caused by a DNA virus classified in the Asfarviridae family, genus Asfivirus (1). The pathogen is an arthropod-borne highly complex enveloped double-stranded DNA virus which primarily replicates in the host cell cytoplasm $(2,3)$. The virus is easily transmitted since it is extremely stable and persists under a variety of environmental conditions, for up to several months, thus creating a requirement for implementation of strict biosecurity measures to prevent transmission (4). The virus causes a highly contagious hemorrhagic disease in pigs that produces a wide spectrum of clinical syndromes ranging from rapid lethality to relatively mild symptoms. The internal lesions closely resemble those of the unrelated classical swine fever virus but with higher morbidity and mortality rates (5). ASF is an economically important disease that is currently enzootic in sub-Saharan Africa (24 genotypes described based on the sequence of the c-terminus of the p72 surface antigen) and Sardinia (p72 genotype 1). In 2007 a genotype II virus from Southeast Africa reached the Caucasus region and subsequently Russia and Eastern Europe (6, 7). Multiple outbreaks almost certainly originating from the single index case in the Caucasus have recently (from August 2018) been reported in China, Vietnam, Cambodia, Laos, North and South Korea, 
Philippines, and Timor-Leste (OIE, December 2019). The consequences for the 450 million pigs in China are already devastating. Given the level of global interconnectivity of the world economy and the stability of the virus, there is a high risk of spread to ASFV-free large scale pork producing countries, such as U.S.A, Germany, Denmark, and Brazil (7).

As the causal agent of one of the most severe diseases of domestic pigs that spreads easily, in the case of the major genotype II pandemic facilitated by the movement of wild boar in which the disease is lethal, ASFV has many sanitary and socio-economic consequences which significantly impact the national and international trade of animals and animal products (8). At present, mass slaughter of infected and incontact pigs with proper disposal and disinfection is the only way to manage outbreaks. The host cell entry and replication mechanisms utilized by the virus, the strategies it uses to evade host defense systems, identity of viral proteins that are important in causing an effective host immune response, and the protective immune mechanisms involved, are gradually being discovered (9). Since completion of sequencing of the first entire virus genome (10), a concerted effort has been made to analyze the genomes and predicted proteome of multiple isolates to generate knowledge that is vital for designing innovative disease control strategies, which include an effective vaccine against various ASFV genotypes (11-14).

Attempts to develop a safe vaccine for protection of pigs against ASFV have continued without significant success from the time ASFV was first isolated (15). Without a safe and efficacious vaccine, pig farmers in the affected areas are venerable to the disease whose prevention depends exclusively on ensuring that infected pigs, contaminated feeds and materials, or fomites (for example virus on the clothes or shoes of pig workers) are not introduced into areas that are ASFV-free (16). All eradication programs that have proven successful involved the prompt diagnosis, quarantine, slaughter, and properly discarding all animals in infected sites (17-19). Subsequently, surveillance of all pig farms within a specific region must be conducted to ensure maintenance of disease-free zones.

The focus of this review is the historical progress made so far in regards to the efforts directed at development of safe and effective vaccines for protection of swine against ASF virus. Several prospective vaccine candidates have been evaluated and some novel candidates are being developed and tested. The development strategies for the vaccine can be divided basically into these broad categories; live attenuated ASF viruses, inactivated ASF virus, live-vectored subunit, mammalian expression plasmid DNA-based, recombinant protein-basedsubunit candidates, and a combination of the above (20). Live attenuated virus can be generated by deletion of genes encoding virulent factors for safe induction of protective immunity (21, 22). Some ASFV antigens have been identified and used to generate recombinant proteins for evaluation of protein-based candidate immunogens (23). Direct delivery of viral nucleic material into host cells can result in de novo gene expression and the expressed antigen can elicit immune responses. Live-vectored vaccines are similar to nucleic acid-based vaccines except that the genes encoding target antigens are delivered into the host cell by employing non-pathogenic attenuated virus or bacteria. There are constraints to all of these approaches that have prevented rapid progress in development of safe and cost effective vaccines to control the virus.

\section{LIVE ATTENUATED ASFV VACCINE CANDIDATES}

A range of mutant viruses have been either isolated from the field or experimentally generated and tested for their ability to safely induce protective immunity in pigs and wild boars. Attenuated viruses can be either naturally occurring low-virulence isolates or virulent strains attenuated by deletion of defined DNA sequences encoding virulence factors. Whole virus-based vaccines can be sub-divided into two categories: live attenuated viruses and inactivated or killed viruses.

\section{Live Attenuated Vaccine Candidates}

Live attenuated ASFV vaccine candidates can induce protective immunity, but the use of naturally attenuated strains of ASFV has the potential to cause post-vaccination reactions and side effects. Although it has previously been demonstrated that following subclinical infections of domestic pigs with low virulent strains of ASFV, immunity against homologous, but not heterologous, challenge was conferred (24). A Portuguese group was the first to demonstrate subclinical infections of domestic pigs with low virulent strains of ASFV (20). They found that pigs immunized with the naturally occurring ASFV NH/P68 virus, which was isolated subsequent to the introduction of a genotype I virus into that country from Angola, were protected against challenge with virulent ASFV L60 and this correlated with increased NK cell activity (20). Immunization of pigs with low virulence ASFV isolates provide varying levels of protection against challenge with virulent virus. For instance, pigs immunized with naturally attenuated ASFV strains NH/P68 or the Ornithodoros erraticus tick-derived OURT88/3 were protected following challenge with closely related ASFV strains and those challenged with heterologous strains were partially protected $(20,25-27)$. The level of protection in both cases varied from 60 to $100 \%$ (2632). These outcomes provided useful data concerning immune parameters involved in protection. Both antibodies and cytotoxic $\mathrm{CD}^{+} \mathrm{T}$ cells were demonstrated to play important roles in conferring protection $(25,33-35)$.

Despite the ability to induce protective antibody and $\mathrm{T}$ cell responses, naturally attenuated isolates have been associated with adverse side effects and safety concerns (29). To improve safety, mutant viruses have been generated with deletions of genes involved in virulence and progress of clinical disease (DP96R and DP71L) and inhibition of IFN- $\gamma$ (A276R) $(23,36)$. However, varying levels of protection were observed in immunized pigs. Virulent virus isolates can be attenuated by deletion of rationally selected genes encoding virulence factors to obtain attenuated virus that can safely induce protective immunity. However, deletion of some genes has been shown to significantly reduce the virulence of the virus in pigs, whereas deletion of others had no apparent effect (37). In one study, deletion of virulence genes 
DP96R and DP71L from the ASFV OURT88/3 isolate reduced its ability to protect against challenge with virulent virus OURT88/1 isolate, whereas in another study, $60-100 \%$ protection was observed following challenge with heterologous virulent ASFV Armenia $07(23,29)$. It has been shown that deletion of IFN$\gamma$ inhibitor genes DP148R, MGF360, and 530/505 genes from ASFV Benin97/1 isolate induced protective immune responses against challenge $(38,39)$. By contrast, deletion of the early virus protein L83L from the ASFV Georgia 2007 isolate did not reduce viral virulence in experimentally infected swine, and no challenge studies were performed (40). Recently, immunization of pigs with a naturally attenuated genotype II ASFV Lv17/WB/Rie1 isolated from wild boars in Latvia conferred protection upon challenge through contact with animals infected with virulent ASFV (41).

Immunization with attenuated virus, rather than with selected antigens, is advantageous since it elicits immune responses against all the viral antigens that are normally encountered by the host during the course of an infection, and it may therefore be more effective. Several attenuated viruses have been tested for their ability to induce immune protection (Table 1). Among the genes that have been deleted in these attenuated viruses are; EP402R (a homolog of CD2), B119L, DP71L, K169R, DP96R, E165R, EP153R, MGF360/530, A224L, A238L, and E269R (46). Many of the proteins encoded by the deleted or inactivated genes in these attenuated constructs have predicted functions based on sequence identity, and biological observations. The product encoded by EP402R is involved in mediating hemadsorption of RBCs to infected host macrophages and extracellular virus particles; DP71L exhibits similarity to a Herpes simplex virus (HSV) neurovirulence factor; KI69R encodes Thymidine kinase; E165R encodes a dUTPase; EP153R encodes a C-type lectin; $\mathrm{A} 22 \mathrm{~L}$ is an IAP apoptosis inhibitor that presumably prevents host programmed cell death; A238L is an inhibitor of host cell transcription; and E296R encodes an AP endonuclease Class II (47). The function of the MGFs, including families 360 and 530 is unknown, although some of the proteins contain predicted signal peptides, suggesting secretion and interaction with host proteins (47). B119L has sequence identity to several yeast proteins including ERV1 which functions in oxidative phosphorylation (4).

Deleting certain genes from the genome of a virulent ASFV isolate affects pathogenesis in pigs (48). For example, when the EP402R gene was deleted, there was reduction in virus dissemination through tissues (49). However, recent studies showed that deletion of the EP402R gene from the genotype I BA71 isolate attenuated the virus and the mutant conferred protection against challenge with homologous virulent BA71 virus, and also heterologous E75 (Genotype 1) and Georgia 2007/1 (Genotype II) viruses (30). Surprisingly, deletion of the DP71L and DP96R genes from the ASFV strain OURT88/3 decreased its protective capacity in pigs following challenge with virulent virus (23). Recent studies have also shown that deletion of the B119L, DP71L/NL, and DP96R/UK genes from the ASFV Georgia 2007/1 strain reduced its replication efficiency, but the mutant did not protect immunized pigs against challenge with parental virus (45).
Deletion of MGF 360, MGF 505, or B119GL genes attenuated the ASFV Georgia 2007/1 isolate and the respective mutant virus elicited immune responses that protected immunized pigs against homologous virulent challenge. However, protection was not observed when both MGF 360/505 and B119GL genes were deleted, indicating that deletion of multiple genes can sometimes significantly reduce protective capacity of the resulting mutant $(42,43,50)$. However, by contrast, improved protection and safety was observed when the DP96R/UK and B119GL genes were simultaneously deleted from the ASFV Georgia 2007/1 isolate (44). In the case of other specific virulence genes, such as Thymidine Kinase (TK), although less pathogenic viruses were generated, the performance of the resultant mutants was not consistent. Notably, deletion of the TK gene in Georgia 2007/1 and Malawi strains attenuated the viruses, however the Malawi strain, but not the Georgia 2007/1 strain, induced protective responses in immunized pigs $(30,51,52)$. The outcome suggests that the effect of gene deletions on the ability of the virus to elicit immune protection is strain-specific (52). Thus, additional new knowledge is required for rational development of live attenuated ASFV candidate vaccine and that evaluation has to be on a case by case basis.

Although attenuated ASFV is currently the most promising vaccine candidate, there are still major challenges that need to be addressed. These include safety concerns because the viruses are not sufficiently attenuated, requirement for high biocontainment for production of the attenuated virus, availability of suitable cell lines and optimization of culture conditions for vaccine virus scale up which remains a key constraint (53).

\section{Inactivated ASFV Vaccines}

Efforts to generate inactivated or killed ASFV vaccines capable of conferring protection have been unproductive (54-57). One recent study showed that although an inactivated preparation of the ASFV Armenia08 formulated with contemporary adjuvants elicited ASFV specific antibodies, there was no protection upon challenge with homologous virulent virus (11). This outcome raises serious questions regarding the role of antibodies in protection against ASFV, but it is possible that the antibodies elicited by this particular immunogen failed to confer protection. Although antibodies have been implicated in protection against ASFV, the antibody target(s), the actual effector mechanism(s) or the isotype(s) involved, remains unknown (16).

\section{SUBUNIT VACCINES}

Subunit vaccines utilize a defined pathogen structural, nonstructural or unassigned proteins as antigens to elicit protective immune responses (58). This is accomplished by using a gene encoding a candidate antigen to generate recombinant antigen that is formulated with an adjuvant. Alternatively, the gene can be used to generate a live-vectored recombinant construct for in vivo antigen expression. Several antigens, including p12, p30, p54, and p72, have been evaluated for their protective potential as recombinant proteins. Antibodies against p12 and p72 have been shown to hinder binding of the virus to the host cells, while antibodies against p30 protein prevents the 
TABLE 1 | Live attenuated ASFV vaccines.

\begin{tabular}{|c|c|c|c|}
\hline Strain & Vaccine virus & Protection & References \\
\hline \multirow{3}{*}{$\begin{array}{l}\text { Naturally } \\
\text { attenuated } \\
\text { OURT88/3 }\end{array}$} & OURT88/3 & $\begin{array}{l}\text { Homologous OURT88/3 } \\
\text { strain }\end{array}$ & (23) \\
\hline & & $\begin{array}{l}\text { Heterologous } \\
\text { OURT88/1 strain }\end{array}$ & (28) \\
\hline & & $\begin{array}{l}\text { Heterologous Benin } \\
97 / 1 \text {, Uganda } 65 \text { strains }\end{array}$ & (28) \\
\hline $\mathrm{NH} / \mathrm{P} 68$ & NH/P68 & $\begin{array}{l}\text { Heterologous L60, } \\
\text { Armenia } 07 \text { strains }\end{array}$ & $(20,32)$ \\
\hline $\begin{array}{l}\text { Gene- } \\
\text { deletion } \\
\text { OURT/88/3 }\end{array}$ & $\begin{array}{l}\text { OURT/88/3 } \mathrm{DP} 71 \mathrm{~L} \\
\Delta \mathrm{DP} 96 \mathrm{R}\end{array}$ & $\begin{array}{l}\text { Homologous } \\
\text { OURT/88/1strain }\end{array}$ & (23) \\
\hline \multirow[t]{5}{*}{$\mathrm{NH} / \mathrm{p} 68$} & $\mathrm{NH} / \mathrm{P} 68 \Delta \mathrm{A} 238 \mathrm{~L}$ & Homologous L60 strain & $(32)$ \\
\hline & & $\begin{array}{l}\text { Heterologous Armenia } \\
07 \text { strain }\end{array}$ & $(32)$ \\
\hline & $\mathrm{NH} / \mathrm{P} 68 \Delta \mathrm{EP} 153 \mathrm{R}$ & Homologous L60 strain & (32) \\
\hline & NH/P68 $\Delta$ A224L & Homologous L60 strain & (32) \\
\hline & & $\begin{array}{l}\text { Heterologous Armenia } \\
07 \text { strain }\end{array}$ & $(32)$ \\
\hline \multirow[t]{2}{*}{ Benin97/1 } & Benin $97 / 1 \Delta$ MGF & $\begin{array}{l}\text { Homologous Benin 97/1 } \\
\text { strain }\end{array}$ & (38) \\
\hline & $\begin{array}{l}\text { Benin } \\
97 / 1 \Delta \text { DP148R }\end{array}$ & $\begin{array}{l}\text { Homologous Benin 97/1 } \\
\text { strain }\end{array}$ & (39) \\
\hline \multirow[t]{6}{*}{$\begin{array}{l}\text { Georgia } \\
07 / 1\end{array}$} & Georgia 07/1 $\Delta 9 \mathrm{G} L$ & $\begin{array}{l}\text { Homologous Georgia } \\
\text { 07/1 strain }\end{array}$ & $(42)$ \\
\hline & Georgia 07/1 $\Delta$ MGF & $\begin{array}{l}\text { Homologous Georgia } \\
\text { 07/1 strain }\end{array}$ & $(43)$ \\
\hline & Georgia 07/1 $\Delta 9 \mathrm{GL}$ & $\begin{array}{l}\text { Homologous Georgia } \\
\text { 07/1 strain }\end{array}$ & $(44)$ \\
\hline & $\triangle \mathrm{DP} 96 \mathrm{R} / \mathrm{UK}$ & & \\
\hline & $\begin{array}{l}\text { Georgia } \\
07 / 1 \Delta \mathrm{B} 119 /\end{array}$ & No protection & \\
\hline & $\Delta \mathrm{DP} 71 \mathrm{~L} / \triangle \mathrm{DP} 96 \mathrm{R}$ & & $(45)$ \\
\hline Ba71 & $\mathrm{Ba} 71 \Delta \mathrm{EP} 402 \mathrm{R}$ & $\begin{array}{l}\text { Heterologous E75 and } \\
\text { Georgia 07/1 strains }\end{array}$ & (30) \\
\hline
\end{tabular}

TABLE 2 | Protein subunit candidate vaccines.

\begin{tabular}{llll}
\hline ASFV proteins & Expression system & Protection & References \\
\hline CD2v & Baculovirus expressed & Partial protection & $(37)$ \\
p54, p30 & Baculovirus expressed & Protection & $(48)$ \\
p54, p30, p72 & Baculovirus expressed & Partial protection & $(60)$ \\
CD2v and C-type Lectin & Baculovirus expressed & Protection & (27) \\
\hline
\end{tabular}

virus from entering cells $(37,46,48,59)$. However, p12-specific antibodies induced in both natural infections and in animals inoculated with inactivated virus or recombinant $\mathrm{p} 12$ protein, do not block virus binding to the host cell or neutralize virus infectivity (59).

The p30 and p54 proteins mediate interactions between ASFV and host cells and simultaneous interference with the interactions of these two proteins with the host cells has a complementary effect in antibody-mediated protection (48). Some preliminary vaccination experiments using these recombinant proteins gave promising results and these could be followed up with other combinations of recombinant proteins, either as purified proteins, or recombinant live-vectored virus constructs. For instance, baculovirus-expressed p30 and p54 elicited antibodies that protected pigs against challenge with ASFV E75CV1-4 (48). However, in another study, antibodies elicited against p30, p54, and p72 were not sufficient to confer protection against challenge with the ASFV Pr4 isolate (60). Another study showed that immunization of pigs with baculovirusexpressed EP402R antigen, a viral transmembrane protein, elicited hemadsorption inhibition antibodies and conferred partial protection against lethal challenge (37). Moreover, immunization of pigs with a combination of baculovirusexpressed EP402R and C-type Lectin, induced a significant level of protection following challenge with homologous ASFV (Table 2) (27).

\section{LIVE-VECTORED AND DNA-BASED SUBUNIT VACCINE CANDIDATES}

Gene expression vectors, either viral, bacterial, or plasmid-based have been used as antigen delivery platforms that can be tailored to elicit a desired immune response (Table 3). Only a few studies have been conducted to evaluate immunogenicity and protective efficacy of prototype vectored ASFV subunit vaccine candidates. Argilaguet et al. (49) showed that immunization of pigs with BacMam-sHAPQ, a baculovirus-based construct encoding p30, p54, and secretory hemagglutinin or sHA, induced antigenspecific T-cell responses in pigs. Following challenge, 4/6 of the immunized pigs, but not the negative controls, were free of the virus (49). A recombinant modified vaccinia virus Ankara (MVA) expressing the p72, EP402R, and EP153R antigens, induced $\mathrm{T}$ cell responses, but the animals were not challenged to determine whether the induced responses were protective (61). Alphavirus expressing ASFV p30, p54, or p72 were tested for immunogenicity in pigs and the results suggested that an attenuated live virus boost of an initial immunization of a vector-expressed antigen may broaden humoral epitope response (65). It has recently been shown that cocktails of adenoviruses expressing multiple ASFV (Georgia 2007/1) antigens [p32, p54, pp62, p72, A104R, K205R, B438L, EP402R $\Delta$ PRR, B602L, B119L, and $A 151 R]$, induced robust cellular and antibody responses $(62,63)$. Although highly immunogenic, the adenovirus-vectored ASFV antigen cocktail did not confer significant protection following intranasal challenge with ASFV Georgia2007/1 isolate (64), whereas in a sub-study, protection was observed in 5/9 of the vaccinated animals (64). This study further suggested that antibodies induced by one of these adenovirus vectored antigen cocktails may be counter-protective, since delivery using an adjuvant that induced lower levels of antibodies, resulted in enhanced protection of pigs following virus challenge (64). Moreover, recent studies has also shown that a cocktail of Adenovirus and Modified Ankara Virus expressing up to 18 antigens [I215R, I73R, CP530R [pp62], CP204L [p32], MGF1105L, B646L [p72], MGF110-4L, M448R, L8L, E146L, C129R, 
TABLE 3 | Live vectored and DNA sub-unit vaccine candidates.

\begin{tabular}{|c|c|c|c|}
\hline $\begin{array}{l}\text { ASFV } \\
\text { proteins/genes }\end{array}$ & $\begin{array}{l}\text { Expression } \\
\text { system }\end{array}$ & Protection & References \\
\hline $\begin{array}{l}\text { Vectored } \\
\text { p54, p30, sHA }\end{array}$ & BacMam-sHAPQ & Partial protection & (49) \\
\hline $\begin{array}{l}\text { p72, CD2v, and } \\
\text { EP153R }\end{array}$ & $\begin{array}{l}\text { Modified vaccinia } \\
\text { virus ankara }\end{array}$ & No challenge study & (61) \\
\hline $\begin{array}{l}7 \text { and } 12 \text { antigen } \\
\text { cocktails }\end{array}$ & $\begin{array}{l}\text { Adenovirus } \\
\text { vectored }\end{array}$ & No challenge study & $(62,63)$ \\
\hline 7 antigen cocktail & $\begin{array}{l}\text { Adenovirus } \\
\text { vectored }\end{array}$ & Partial protection & (64) \\
\hline 7 antigen cocktail & $\begin{array}{l}\text { Adenovirus } \\
\text { vectored }\end{array}$ & No protection & (64) \\
\hline 12 antigen cocktail & $\begin{array}{l}\text { Adenovirus } \\
\text { vectored }\end{array}$ & No protection & (64) \\
\hline $\begin{array}{l}\text { p30, p54, and } \\
\text { pHA-72 }\end{array}$ & $\begin{array}{l}\text { Alphavirus vectored } \\
\text { prime, } \\
\text { Attenuated } \\
\text { OURT88/3 boost }\end{array}$ & No challenge study & (65) \\
\hline 18 antigen cocktail & $\begin{array}{l}\text { Adenovirus and } \\
\text { MVA vectored }\end{array}$ & No protection & (66) \\
\hline $\begin{array}{l}\text { DNA sub-units } \\
\text { DNA expression } \\
\text { library }\end{array}$ & DNA constructs & Partial protection & (67) \\
\hline $\begin{array}{l}\text { p54/E183L, } \\
\text { p30/CP204L }\end{array}$ & DNA constructs & No protection & $(68,69)$ \\
\hline $\begin{array}{l}\text { Ubiquitin- } \\
\text { CD2v/pEP402R- } \\
\text { p54/E183L- } \\
\text { p30/CP204L }\end{array}$ & DNA constructs & Partial protection & (69) \\
\hline $\begin{array}{l}\text { DNA and } \\
\text { vectored/protein } \\
47 \text { antigen pool }\end{array}$ & $\begin{array}{l}\text { DNA constructs } \\
\text { and vaccinia virus }\end{array}$ & Partial protection & (70) \\
\hline $\begin{array}{l}\mathrm{p} 15, \mathrm{p} 35, \mathrm{p} 54 \text {, and } \\
\pm \mathrm{p} 17 \text { and } \mathrm{p} 32, \mathrm{p} 72 \text {, } \\
\text { CD2v, and } \pm \mathrm{p} 17\end{array}$ & $\begin{array}{l}\text { DNA and protein } \\
\text { vaccine }\end{array}$ & No protection & (71) \\
\hline
\end{tabular}

A151R, MGF110-1L, L10L, K78R, E184L, E165R, and CP312R] used in a prime-boost strategy induced antigen specific immune responses but failed to protect against challenge (66).

DNA vaccination involves inoculation of expression plasmid constructs encoding defined target antigens for expression in mammalian host cells. Potential advantages of DNA vaccination over traditional approaches, include stimulation of B-cell, CD4, and CD8 T-cell responses, improved vaccine stability, the absence of any infectious agent and the relative ease of large-scale production, although production to GMP standard may be more expensive than adenovirus $(72,73)$. A DNA vaccine candidate, pCMV-sHAPQ, encoding ASFV p30 and p54 fused to hemagglutinin extracellular domain (sHA) improved humoral and the cellular responses in pigs, but provided partial protection against lethal challenge with the virulent E75 ASFV-strain (68). Similarly, immunization of pigs with a plasmid construct encoding p30, p54, and sHA genes fused to ubiquitin, elicited $\mathrm{T}$ cell responses but conferred partial protection against challenge with lethal E75 virus strain in the absence of neutralizing antibodies. In this study, protection correlated with presence of sHA-specific $\mathrm{CD}^{+} \mathrm{T}$ cells $(68,69)$. A further experiment demonstrated that immunization of pigs with a DNA expression library of more than 4,000 plasmid clones, each one containing a random Sau IIIa restriction fragments derived from the viral genomic DNA fused to ubiquitin conferred $60 \%$ protection against lethal challenge with the virulent E75 strain (67).

More recent approaches have evaluated several heterologous prime-boost strategies in an attempt to improve protective efficacy of prototype subunit vaccines. Jancovich et al. (70) showed that pigs primed with DNA plasmids encoding 47 ASFV antigens and boosted with recombinant vaccinia virus expressing the same antigens, significantly reduced ASF viral load in the vaccines following challenge with ASFV Georgia 2007/1. However, the same group showed that immunization of pigs with 12 adenovirus constructs expressing selected ASFV antigens and boosting with vaccinia virus expressing cognate antigens, reduced viral loads but the immunized pigs were not protected against challenge with ASFV OURT88/1 (66). Another study has demonstrated that immunization of pigs with recombinant proteins [p15, p32, p54, and \pm p17] and plasmid DNA constructs encoding [p32, p72, EP402R, and \pm p17] in a prime and two booster doses induced cell mediated immune responses and antibodies that were shown to neutralize ASFV in vitro. However, the immunized pigs were not protected against challenge with Armenia 2007 strain (71).

\section{IMMUNIZATION PROTOCOL}

The route of vaccine administration is worthy of further research in the context of immunization protocols. For example, it was observed that the naturally tick attenuated genotype I OURT88/3 virus when administered at low to intermediate doses $\left(10^{3}-10^{4}\right)$ pfu was protective against virulent wild type OURT88/1 challenge when administered intranasally, but not when administered intramuscularly at the same doses (74). Most of the ASFV vaccine candidates tested so far have been delivered by parenteral injection. Recent global consortia call for improved effective vaccine delivery systems, amongst others measures, as a roadmap for developing a vaccine $(75,76)$. An oral bait-based vaccine would be more attractive, particularly for immunization of wild boars and feral pigs. Oral bait-based vaccine delivery has been used for successful immunization of wild animals $(77,78)$. Notably, a vaccinia virus-vectored rabies vaccine [RABORAL] and an adenovirus-vectored oral bait rabies vaccine $[\mathrm{ONRAB}]$ have been used successfully to control rabies in domestic and wild animals in U.S.A and Europe $(77,79,80)$. Recently, an oral ASFV vaccine candidate, attenuated genotype II ASFV (Lv17/WB/Rie1), was tested in wild boars and shown to confer $92 \%$ protection against virulent challenge with ASFV Armo7 isolate (81). The Lv17/WB/Rie1 mutant has potential to be used for ASFV management in domestic pigs and to control ASFV from spreading in wild boar populations. However, 
further studies are needed before the vaccine can be approved for deployment.

\section{CHALLENGE MODELS AND THEIR LIMITATIONS}

Lack of knowledge on the appropriate challenge model relevant to the candidate vaccine limits the development of a safe and efficacious ASFV vaccine. Transmission of ASFV in domestic swine often occurs via direct contact between persistently infected and susceptible animals, via soft ticks in the genus Ornithodoros, or contaminated feed including other pigs that have been slaughtered or succumbed to the disease (82). ASFV epidemiology is complex since infection of domestic pigs typically results in mortality and morbidity, whereas wild suids including warthogs and bushpigs can be infected but they are asymptomatic. There are also different patterns of pathogenesis and clinical outcomes in domestic pigs across different regions of the world where ASFV is endemic. In addition viral pathogenicity may evolve over time and as the virus expands its range into new areas (1). Genetic variability amongst different breeds of swine, which originate from multiple independent domestication events, could be one factor explaining clinical disease why outcomes vary between different infected animals (1). Factors such as husbandry systems and the involvement of wild boar and tick transmission may also be important. Therefore, simulation of most common natural routes of infection and transmission is critical for evaluation of protective efficacy of vaccine candidates. Currently, live attenuated ASFV are the most promising vaccine candidates for eliciting protective immunity, but safety concerns combined with scale-up issues have delayed progress in deployment of these candidates in the field. The BA71 $\triangle \mathrm{EP} 402 \mathrm{R}$ deletion mutant was shown to protect against lethal challenge with both genotype I strains, BA71 and E75 (30). Additionally, $100 \%$ of pigs immunized with the mutant survived lethal challenge with genotype 2 Georgia 2007/1 isolate (30).

The cross protection conferred by BA71 $\triangle \mathrm{EP} 402 \mathrm{R}$ makes this most promising candidate vaccine developed to date. However, biosecurity and biocontainment concerns remain, as well as the requirement to ensure that pigs immunized with this vaccine and others can be differentiated from infected pigs.

Following immunization with candidate vaccines, protection levels vary from 0 to $100 \%$, depending on the breed of pigs, vaccine dose, delivery route, and the virus isolate used for the challenge $(30,63,64,70,81,83,84)$. As mentioned, ideal challenge models should closely resemble natural ASFV transmission in swine and the most common transmission route is likely to be via direct contact through mucosal surfaces (17, 85). Therefore, a novel challenge model, such as incorporating ASFV into feed/liquid for an oral and/or intranasal challenge post-vaccination, may be key to better understanding of the immune responses induced and obtaining protection following challenge. Therefore, to identify protective antigens needed for subunit vaccine development, there is a need to empirically define an appropriate ASFV challenge dose. This is important given that the correlates of protection are not yet available and the optimal antigen(s) for inducing protection have not yet been defined. Additionally, challenging animals immunized with a subunit vaccine candidate with a high dose of virulent ASFV that has been shown to work for evaluating efficacy of attenuated ASFV candidate vaccines may not be appropriate and hinder identification of antigen-specific immune responses that correlate with protection.

To date, the majority of ASFV immunization studies have used intramuscular administration of vaccine and the same route for challenge. Few studies aim to determine effective intranasal challenge doses of ASFV isolates that differ in virulence. The majority of immunization studies have used well-characterized domestic breeds, such as large white or landrace as the target animal for immunization studies $(16,27,32,67,71,74)$. To date, only a few groups have used indigenous breeds of pigs from ASFV endemic areas, such as Africa for vaccination research (83).

The high costs associated with BSL3 biocontainment laboratories and space constraints in such facilities have limited the number of challenge studies performed and hindered long-term monitoring of animals post-challenge. Studies have reported variable duration of monitoring postchallenge, ranging from 17 to $63 \mathrm{DPV}$ and this does not provide consistent data for comparison of vaccine candidates $(41,64,81)$. Thus, vaccine immunization and challenge protocols need to be standardized to allow uniform interpretation of outcomes.

\section{ASFV CANDIDATE VACCINE-INDUCED DISEASE EXACERBATION}

Vaccinated pigs can potentially develop chronic ASF or severe pathology either post-vaccination and/or post-challenge. Following vaccination and challenge more severe clinical disease, when compared to the non-vaccinated animals, has been observed. Jancovich et al. (70) showed that vaccine-induced antibodies correlated with increased viremia. This observation was also supported by outcomes reported in several other studies $(64,70,71)$. In the 1960s, live attenuated vaccines were used to immunize pigs following outbreaks of ASF in Portugal, Spain and Dominican Republic $(53,86)$. Although there were reports of survival and protection from naturally attenuated ASFV used, the biggest concerns with deploying LAVs is safety and the ensuing persistence of chronic forms of ASF in pig populations. Such persistence of chronic clinical signs were observed during evaluation of the attenuated ASFV NH/P68 $\Delta$ A276R, which failed to confer protection against Arm07 challenge (32). In another study, pigs immunized with the ASFV-G- $\Delta$ L83L mutant had severe ASF clinical symptoms, similar to pigs inoculated with the parental ASFV-G virus, and either died from the infection or had to be euthanized (40).

The ASFV causes high mortality rates in domestic swine, regardless of gender and age (87). Another point to be considered is whether gender and sex differences have any effect on vaccination outcome (88). Netherton et al. (66) recently observed a variation in disease outcome between male and female immunized pigs. The authors reported that male immunized pigs 
showed enhanced ASF clinical disease, while female pigs had reduced viremia compared to control pigs (66).

\section{CONCLUSION AND FUTURE PERSPECTIVES}

African swine fever virus causes acute hemorrhagic fever in pigs that results in high mortality and lack of a vaccine limits control to test and mass slaughter of infected and in-contact pigs. Sequencing genomes of attenuated and virulent strains, and targeted gene deletions from virulent strains have revealed genes encoding some of the factors involved in virulence and immune evasion, and with increasing spread of the disease, there is an impetus to sequence genomes of more isolates to identify relevant genes. It is clear that effective immunity depends on both antibody and cellular immune responses. Pigs immunized with naturally low virulence isolates or attenuated viruses produced by targeted gene deletions can induce protection against challenge by wild type virulent viruses. Virus antigens that are potential targets for inducing neutralizing antibodies have been identified and immunization with some of these antigens has been shown to confer partial protection. However, antigens that can elicit protective immunity, especially $\mathrm{CD} 8^{+} \mathrm{T}$ cell targets, have yet to be identified. Although several live attenuated ASFV are

\section{REFERENCES}

1. ASF.ERLf. Standard Operating Procedure for the Detection of Antibodies Against African Swine Fever by Indirect Immunoperoxidase Technique. Madrid: European Union Reference Laboratory (EURL) for ASF, Centro de Investigación en Sanidad Animal (CISA-INIA). Available online at:http:// asf-referencelabinfo/asf/images/ficherosasf/SOP\%202018/SOP-ASF-IPT- 1 _ REV2018pdf.

2. Dixon LK, Chapman D, Abrams C, Rowlands R. Asfivirus. In: Tidona C, Darai G, editors. The Springer Index of Viruses. New York, NY: Springer (2011). p. 79-87. doi: 10.1007/978-0-387-95919-1_9

3. Alonso C, Borca M, Dixon L, Revilla Y, Rodriguez F, Escribano JM. ICTV virus taxonomy profile: Asfarviridae. J General Virol. (2018) 99:613-4. doi: 10.1099/jgv.0.001049

4. Lewis T, Zsak L, Burrage T, Lu Z, Kutish G, Neilan J, Rock DL. An African swine fever virus erv1-alrhomologue, 9gl, affects virion maturation and viral growth in macrophages and viral virulence in swine. J Virol. (2000) 74:1275-85. doi: 10.1128/JVI.74.3.1275-128 5.2000

5. Oura C. Overview of African Swine Fever. Merck manual. (2013) Available online at: https://wwwmerckvetmanualcom/generalized-conditions/africanswine-fever/overview-of-african-swine-fever (accessed December 10, 2019).

6. OIE. African swine fever. In: Linnane S, Edwards S, editors. OIE Terrestrial Manual 2012. Paris: World Organisation for Animal Health (2012).

7. Brown VR, Bevins SN. A review of African swine fever and the potential for introduction into the United States and the possibility of subsequent establishment in feral swine and native ticks. Front Vet Sci. (2018) 5:11. doi: 10.3389/fvets.2018.00011

8. Agüero M, Blasco R, Wilkinson P, Vinuela E. Analysis of naturally occurring deletion variants of African swine fever virus: multigene family 110 is not essential for infectivity or virulence in pigs. Virology. (1990) 176:195-204. doi: 10.1016/0042-6822(90)90244-L

9. Borca M, Carrillo C, Zsak L, Laegreid W, Kutish G, Neilan J, et al. Deletion of a CD2-like gene, 8-DR, from African swine fever virus affects viral infection in domestic swine. J Virol. (1998) 72:2881-9. doi: 10.1128/JVI.72.4.2881-2889.1998 currently the most promising vaccine candidates, further work is needed to address some limitations, in particular scale up, prior to approval for deployment. Importantly, definition of correlates of protection against ASFV will enable rational identification of protective antigens for development of DIVA subunit vaccine. Recent studies have sequenced the warthog (Phacocherus africanus) and bush pig (Potamochoerus larvatus) genomes to better understand mechanisms of tolerance to ASFV infection, and how the disease burden is reduced in these swine species compare to domestic swine (89). This data will support current and future vaccine development strategies by comparing susceptible to resistant pig species.

\section{AUTHOR CONTRIBUTIONS}

WM, SL, RB, and SW planned and wrote the paper. HS, GM, and NS conducted literature review and wrote the paper.

\section{FUNDING}

WM was supported by the Agriculture and Food Research Initiative Competitive Award Nos. 2016-67015-25041 and 201967015-29835 from the USDA National Institute of Food and Agriculture.

10. Yáñez RJ, Rodriguez JM, Nogal ML, Yuste L, Enriquez C, Rodriguez JF, et al. Analysis of the complete nucleotide sequence of African swine fever virus. Virology. (1995) 208:249-78. doi: 10.1006/viro.1995.1149

11. Blome S, Gabriel C, Beer M. Modern adjuvants do not enhance the efficacy of an inactivated African swine fever virus vaccine preparation. Vaccine. (2014) 32:3879-82. doi: 10.1016/j.vaccine.2014.05.051

12. Zhu Z, Meng G. ASFVdb: an integrative resource of African swine fever for genomics and proteomics analysis. bioRxiv. (2019) 670109. doi: $10.1101 / 670109$

13. Herrera-Uribe J, Jiménez-Marín Á, Lacasta A, Monteagudo PL, PinaPedrero S, Rodríguez F, et al. Comparative proteomic analysis reveals different responses in porcine lymph nodes to virulent and attenuated homologous African swine fever virus strains. Vet Res. (2018) 49:90. doi: 10.1186/s13567-018-0585-z

14. Portugal R, Coelho J, Höper D, Little NS, Smithson C, Upton C, et al. Related strains of African swine fever virus with different virulence: genome comparison and analysis. J General Virol. (2015) 96:408-19. doi: 10.1099/vir.0.070508-0

15. Montgomery RE. Immunization With Attenuated Virus - Annual Reports of the Chief Veterinary Research Officer. Nairobi: Annual Report of the Agricultural Department (1921-1927)

16. Sanchez-Cordon P, Montoya M, Reis A, Dixon L. African swine fever: a re-emerging viral disease threatening the global pig industry. Vet J. (2018) 233:41-8. doi: 10.1016/j.tvjl.2017.12.025

17. Sánchez-Vizcaíno J, Mur L, Gomez-Villamandos J, Carrasco L. An update on the epidemiology and pathology of African swine fever. J Comp Pathol. (2015) 152:9-21. doi: 10.1016/j.jcpa.2014.09.003

18. Penrith ML, Vosloo W, Jori F, Bastos AD. African swine fever virus eradication in Africa. Virus Res. (2013) 173:228-46. doi: $10.1016 /$ j.virusres.2012.10.011

19. Arias M, Sánchez-Vizcaíno J. African swine fever eradication: the spanish model. In: Morilla A, Yoo K-J, Zimmerman JJ, editors. Trends in Emerging Viral Infections of Swine. New Jersey, NY: Wiley (2002). p. 133-9. doi: 10.1002/9780470376812.ch4c

20. Leitão A, Cartaxeiro C, Coelho R, Cruz B, Parkhouse R, Portugal FC, et al. The non-haemadsorbing African swine fever virus isolate ASFV/NH/P68 provides 
a model for defining the protective anti-virus immune response. J General Virol. (2001) 82:513-23. doi: 10.1099/0022-1317-82-3-513

21. Revilla Y, Perez-Nunez D, Richt JA. African swine fever virus biology and vaccine approaches. Adv Virus Res. (2018) 100:41-74. doi: 10.1016/bs.aivir.2017.10.002

22. Arias M, De la Torre A, Dixon L, Gallardo C, Jori F, Laddomada A, et al. Approaches and perspectives for development of African swine fever virus vaccines. Vaccines. (2017) 5:35. doi: 10.3390/vaccines5040035

23. Abrams CC, Goatley L, Fishbourne E, Chapman D, Cooke L, Oura CA, et al. Deletion of virulence associated genes from attenuated African swine fever virus isolate OUR T88/3 decreases its ability to protect against challenge with virulent virus. Virology. (2013) 443:99-105. doi: 10.1016/j.virol.2013.04.028

24. Hamdy F, Dardiri A. Clinical and immunologic responses of pigs to African swine fever virus isolated from the Western Hemisphere. Am J Vet Res. (1984) 45:711-4.

25. Oura C, Denyer M, Takamatsu H, Parkhouse R. In vivo depletion of CD8 ${ }^{+}$ T lymphocytes abrogates protective immunity to African swine fever virus. $J$ General Virol. (2005) 86:2445-50. doi: 10.1099/vir.0.81038-0

26. Boinas F, Hutchings G, Dixon L, Wilkinson P. Characterization of pathogenic and non-pathogenic African swine fever virus isolates from Ornithodoros erraticus inhabiting pig premises in Portugal. J General Virol. (2004) 85:217787. doi: 10.1099/vir.0.80058-0

27. Burmakina G, Malogolovkin A, Tulman E, Zsak L, Delhon G, Diel D, et al. African swine fever virus serotype-specific proteins are significant protective antigens for African swine fever. J General Virol. (2016) 97:1670-5. doi: 10.1099/jgv.0.000490

28. King K, Chapman D, Argilaguet JM, Fishbourne E, Hutet E, Cariolet R, et al. Protection of European domestic pigs from virulent African isolates of African swine fever virus by experimental immunisation. Vaccine. (2011) 29:4593-600. doi: 10.1016/j.vaccine.2011.04.052

29. Gallardo C, Soler A, Nieto R, Mur L, Pérez C, Pelayo V, et al. Protection of European domestic pigs from Armenia virulent African swine fever virus by experimental immunisation using the attenuated and non-haemadsorbing African swine fever virus isolate ASFV/NH/P68. In: Proceedings of the 9th Annual ESVV Congress Madrid:109. Madrid (2012).

30. Monteagudo PL, Lacasta A, López E, Bosch L, Collado J, Pina-Pedrero $\mathrm{S}$, et al. BA71 $\triangle \mathrm{CD} 2$ : a new recombinant live attenuated African swine fever virus with cross-protective capabilities. J Virol. (2017) 91:e01058-17. doi: 10.1128/JVI.01058-17

31. Malogolovkin A, Burmakina G, Tulman E, Delhon G, Diel D, Salnikov N, et al. African swine fever virus CD2v and C-type lectin gene loci mediate serological specificity. J General Virol. (2015) 96:866-73. doi: 10.1099/jgv.0.000024

32. Gallardo C, Sánchez EG, Pérez-Núñez D, Nogal M, de León P, Carrascosa ÁL, et al. African swine fever virus (ASFV) protection mediated by NH/P68 and NH/P68 recombinant live-attenuated viruses. Vaccine. (2018) 36:2694-704. doi: 10.1016/j.vaccine.2018.03.040

33. de León P, Bustos MJ, Carrascosa AL. Laboratory methods to study African swine fever virus. Virus Res. (2012) 173:168-79. doi: 10.1016/j.virusres.2012.09.013

34. Onisk D, Borca M, Kutish S, Kramer E, Irusta P, Rock DL. Passively transferred African swine fever virus antibodies protect swine against lethal infection. Virology. (1994) 198:350-4. doi: 10.1006/viro.1994.1040

35. Zheng ZM, He PJ, Baker CC. Structural, functional, and protein binding analyses of bovine papillomavirus type 1 exonic splicing enhancers. J Virol. (1997) 71:9096-107. doi: 10.1128/JVI.71.12.9096-9107.1997

36. Correia S, Ventura S, Parkhouse RM. Identification and utility of innate immune system evasion mechanisms of ASFV. Virus Res. (2013) 173:87-100. doi: 10.1016/j.virusres.2012.10.013

37. Ruiz-Gonzalvo F, Rodriguez F, Escribano J. Functional and immunological properties of the baculovirus-expressed hemagglutinin of African swine fever virus. Virology. (1996) 218:285-9. doi: 10.1006/viro.1996.0193

38. Reis AL, Abrams CC, Goatley LC, Netherton C, Chapman DG, SanchezCordon P, et al. Deletion of African swine fever virus interferon inhibitors from the genome of a virulent isolate reduces virulence in domestic pigs and induces a protective response. Vaccine. (2016) 34:4698-705. doi: 10.1016/j.vaccine.2016.08.011

39. Reis AL, Goatley LC, Jabbar T, Sanchez-Cordon PJ, Netherton CL, Chapman $\mathrm{DA}$, et al. Deletion of the African swine fever virus gene DP148R does not reduce virus replication in culture but reduces virus virulence in pigs and induces high levels of protection against challenge. J Virol. (2017) 91:e0142817. doi: 10.1128/JVI.01428-17

40. Borca MV, O’Donnell V, Holinka LG, Ramírez-Medina E, Clark BA, Vuono EA, et al. The L83L ORF of African swine fever virus strain Georgia encodes for a non-essential gene that interacts with the host protein IL-1 $\beta$. Virus Res. (2018) 249:116-23. doi: 10.1016/j.virusres.2018. 03.017

41. Gallardo C, Soler A, Rodze I, Nieto R, Cano-Gómez C, Fernandez-Pinero J, et al. Attenuated and non-haemadsorbing (non-HAD) genotype II African swine fever virus (ASFV) isolated in Europe, Latvia 2017. Transbound Emerg Dis. (2019) 66:1399-404. doi: 10.1111/tbed.13132

42. O’Donnell V, Holinka LG, Krug PW, Gladue DP, Carlson J, Sanford B, et al. African swine fever virus Georgia 2007 with a deletion of virulence-associated gene 9GL (B119L), when administered at low doses, leads to virus attenuation in swine and induces an effective protection against homologous challenge. $J$ Virol. (2015) 89:8556-66. doi: 10.1128/JVI.00969-15

43. O’Donnell V, Holinka LG, Gladue DP, Sanford B, Krug PW, Lu X, et al. African swine fever virus Georgia isolate harboring deletions of MGF360 and MGF505 genes is attenuated in swine and confers protection against challenge with virulent parental virus. J Virol. (2015) 89:6048-56. doi: 10.1128/JVI.00 554-15

44. O’Donnell V, Risatti GR, Holinka LG, Krug PW, Carlson J, VelazquezSalinas L, et al. Simultaneous deletion of the 9GL and UK genes from the African swine fever virus Georgia 2007 isolate offers increased safety and protection against homologous challenge. J Virol. (2017) 91:e01760-16. doi: 10.1128/JVI.01760-16

45. Ramirez-Medina E, Vuono E, O’Donnell V, Holinka LG, Silva E, Rai A, et al. Differential effect of the deletion of African swine fever virus virulenceassociated genes in the induction of attenuation of the highly virulent georgia strain. Viruses. (2019) 11:599. doi: 10.3390/v11070599

46. Gomez-Puertas P, Rodriguez F, Oviedo JM, Ramiro-Ibanez F, Ruiz-Gonzalvo F, Alonso C, et al. Neutralizing antibodies to different proteins of African swine fever virus inhibit both virus attachment and internalization. J Virol. (1996) 70:5689-94. doi: 10.1128/JVI.70.8.5689-5694.1996

47. Dixon LK, Chapman DA, Netherton CL, Upton C. African swine fever virus replication and genomics. Virus Res. (2013) 173:3-14. doi: 10.1016/j.virusres.2012.10.020

48. Gómez-Puertas P, Rodríguez F, Oviedo JM, Brun A, Alonso C, Escribano JM. The African swine fever virus proteins p54 and p30 are involved in two distinct steps of virus attachment and both contribute to the antibody-mediated protective immune response. Virology. (1998) 243:461-71. doi: 10.1006/viro.1998.9068

49. Argilaguet JM, Pérez-Martín E, López S, Goethe M, Escribano J, Giesow $\mathrm{K}$, et al. BacMam immunization partially protects pigs against sublethal challenge with African swine fever virus. Antiviral Res. (2013) 98:61-5. doi: 10.1016/j.antiviral.2013.02.005

50. O’Donnell V, Holinka LG, Sanford B, Krug PW, Carlson J, Pacheco JM, et al. African swine fever virus Georgia isolate harboring deletions of 9GL and MGF360/505 genes is highly attenuated in swine but does not confer protection against parental virus challenge. Virus Res. (2016) 221:8-14. doi: 10.1016/j.virusres.2016.05.014

51. Moore D, Zsak L, Neilan J, Lu Z, Rock DL. The African swine fever virus thymidine kinase gene is required for efficient replication in swine macrophages and for virulence in swine. J Virol. (1998) 72:10310-5. doi: 10.1128/JVI.72.12.10310-10315.1998

52. Sanford B, Holinka L, O’Donnell V, Krug P, Carlson J, Alfano M, et al. Deletion of the thymidine kinase gene induces complete attenuation of the Georgia isolate of African swine fever virus. Virus Res. (2016) 213:165-71. doi: 10.1016/j.virusres.2015.12.002

53. Sánchez-Vizcaíno J, Mur L, Martínez-López B. African swine fever: an epidemiological update. Transbound Emerg Dis. (2012) 59:27-35. doi: $10.1111 /$ j.1865-1682.2011.01293.x

54. Stone S, Hess W. Antibody response to inactivated preparations of African swine fever virus in pigs. Am J Vet Res. (1967) 28:475-81.

55. Forman A, Wardley R, Wilkinson P. The immunological response of pigs and guinea pigs to antigens of African swine fever virus. Arch Virol. (1982) 74:91-100. doi: $10.1007 / \mathrm{BF} 01314703$ 
56. Kihm U, Ackermann M, Mueller H, Pool R. African swine fever. In: Becker Y, editor. Approaches to Vaccination. New York, NY: Springer (1987). doi: 10.1007/978-1-4613-2343-3_10

57. Mebus CA. African swine fever. Adv Virus Res. (1988) 35:251-69. doi: 10.1016/S0065-3527(08)60714-9

58. Gaudreault NN, Richt JA. Subunit Vaccine Approaches for African Swine Fever Virus. Vaccines. (2019) 7:56. doi: 10.3390/vaccines7020056

59. Angulo A, Vinuela E, Alcami A. Inhibition of African swine fever virus binding and infectivity by purified recombinant virus attachment protein p12. J Virol. (1993) 67:5463-71. doi: 10.1128/JVI.67.9.5463-5471.1993

60. Neilan JG, Zsak L, Lu Z, Burrage TG, Kutish GF, Rock DL. Neutralizing antibodies to African swine fever virus proteins p30, p54, and p72 are not sufficient for antibody-mediated protection. Virology. (2004) 319:337-42. doi: 10.1016/j.virol.2003.11.011

61. Lopera-Madrid J, Osorio JE, He Y, Xiang Z, Adams LG, Laughlin RC, et al. Safety and immunogenicity of mammalian cell derived and Modified Vaccinia Ankara vectored African swine fever subunit antigens in swine. Vet Immunol Immunopathol. (2017) 185:20-33. doi: 10.1016/j.vetimm.2017.01.004

62. Lokhandwala S, Waghela SD, Bray J, Martin CL, Sangewar N, Charendoff $\mathrm{C}$, et al. Induction of robust immune responses in swine by using a cocktail of adenovirus-vectored African swine fever virus antigens. Clin Vaccine Immunol. (2016) 23:888-900. doi: 10.1128/CVI.00395-16

63. Lokhandwala S, Waghela SD, Bray J, Sangewar N, Charendoff C, Martin $\mathrm{CL}$, et al. Adenovirus-vectored novel African Swine Fever Virus antigens elicit robust immune responses in swine. PLoS ONE. (2017) 12:e0177007. doi: 10.1371/journal.pone.0177007

64. Lokhandwala S, Petrovan V, Popescu L, Sangewar N, Elijah C, Stoian A, et al. Adenovirus-vectored African swine fever virus antigen cocktails are immunogenic but not protective against intranasal challenge with Georgia 2007/1 isolate. Vet Microbiol. (2019) 235:10-20. doi: 10.1016/j.vetmic.2019.06.006

65. Murgia MV, Mogler M, Certoma A, Green D, Monaghan P, Williams DT, et al. Evaluation of an African swine fever (ASF) vaccine strategy incorporating priming with an alphavirus-expressed antigen followed by boosting with attenuated ASF virus. Arch Virol. (2019) 164:359-70. doi: 10.1007/s00705-018-4071-8

66. Netherton CL, Goatley LC, Reis AL, Portugal R, Gault LE, Nieto R, et al. Identification and immunogenicity of African swine fever virus antigens. Front Immunol. (2019) 10:1318. doi: 10.3389/fimmu.2019.01318

67. Lacasta A, Ballester M, Monteagudo PL, Rodríguez JM, Salas ML, Accensi F, et al. Expression library immunization can confer protection against lethal challenge with African swine fever virus. J Virol. (2014) 88:13322-32. doi: 10.1128/JVI.01893-14

68. Argilaguet JM, Pérez-Martín E, Nofrarías M, Gallardo C, Accensi F, Lacasta A, et al. DNA vaccination partially protects against African swine fever virus lethal challenge in the absence of antibodies. PLoS ONE. (2012) 7:e40942. doi: 10.1371/journal.pone.0040942

69. Argilaguet J, Perez-Martin E, Gallardo C, Salguero F, Borrego B, Lacasta A, et al. Enhancing DNA immunization by targeting ASFV antigens to SLA-II bearing cells. Vaccine. (2011) 29:5379-85. doi: 10.1016/j.vaccine.2011. 05.084

70. Jancovich JK, Chapman D, Hansen DT, Robida MD, Loskutov A, Craciunescu $\mathrm{F}$, et al. Immunization of pigs by DNA prime and recombinant vaccinia virus boost to identify and rank African swine fever virus immunogenic and protective proteins. J Virol. (2018) 92:e02219-17. doi: 10.1128/JVI.02219-17

71. Sunwoo SY, Pérez-Núñez D, Morozov I, Sánchez EG, Gaudreault NN, Trujillo JD, et al. DNA-Protein vaccination strategy does not protect from challenge with African swine fever virus Armenia 2007 Strain. Vaccines. (2019) 7:12. doi: 10.3390/vaccines7010012

72. Takamatsu HH, Denyer MS, Lacasta A, Stirling CM, Argilaguet JM, Netherton CL, et al. Cellular immunity in ASFV responses. Virus Res. (2013) 173:110-21. doi: 10.1016/j.virusres.2012.11.009

73. Argilaguet JM, Gallardo C, Nofrarias M, Pujols J, Pérez-Filgueira M, Blanco F, et al. DNA vaccines against African swine fever virus: Relevance of humoral and cellular responses in protection. In: Proceedings of the 20th International Pig Veterinary Society Congress. Durban (2008).

74. Sánchez-Cordón PJ, Chapman D, Jabbar T, Reis AL, Goatley L, Netherton CL, et al. Different routes and doses influence protection in pigs immunised with the naturally attenuated African swine fever virus isolate OURT88/3. Antiviral Res. (2017) 138:1-8. doi: 10.1016/j.antiviral.2016.11.021

75. EU. Blueprint and Roadmap on the Possible Development of a Vaccine for African Swine Fever. (2017). Available online at: https://ec.europa.eu/food/ sites/food/files/safety/docs/cff_animal_vet-progs_asf_blue-print-road-map. pdf (accessed December 10, 2019).

76. Arias M, Jurado C, Gallardo C, Fernández-Pinero J, Sánchez-Vizcaíno J. Gaps in African swine fever: analysis and priorities. Transbound Emerg Dis. (2018) 65:235-47. doi: 10.1111/tbed.12695

77. Maki J, Guiot AL, Aubert M, Brochier B, Cliquet F, Hanlon CA, et al. Oral vaccination of wildlife using a vaccinia-rabies-glycoprotein recombinant virus vaccine (RABORAL V-RG®): a global review. Vet Res. (2017) 48:57. doi: 10.1186/s13567-017-0459-9

78. Monger V, Stegeman J, Dukpa K, Gurung R, Loeffen W. Evaluation of oral bait vaccine efficacy against classical swine fever in village backyard pig farms in Bhutan. Transbound Emerg Dis. (2016) 63:e211-8. doi: 10.1111/tbed.12333

79. Fehlner-Gardiner C, Rudd R, Donovan D, Slate D, Kempf L, Badcock J.

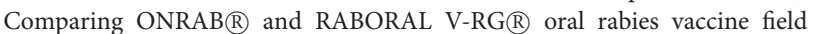
performance in raccoons and striped skunks, New Brunswick, Canada, and Maine, USA. J Wildl Dis. (2012) 48:157-67. doi: 10.7589/0090-3558-48.1.157

80. Mainguy J, Fehlner-Gardiner C, Slate D, Rudd RJ. Oral rabies vaccination

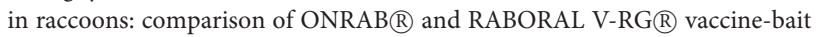
field performance in Québec, Canada and Vermont, USA. J Wildl Dis. (2013) 49:190-3. doi: 10.7589/2011-11-342

81. Barasona JA, Gallardo C, Cadenas-Fernández E, Jurado C, Rivera B, Rodríguez-Bertos A, et al. First oral vaccination of Eurasian wild boar against African swine fever virus genotype II. Front Vet Sci. (2019) 6:137. doi: $10.3389 /$ fvets.2019.00137

82. Guinat C, Gogin A, Blome S, Keil G, Pollin R, Pfeiffer DU, et al. Transmission routes of African swine fever virus to domestic pigs: current knowledge and future research directions. Vet Record. (2016) 178:262-7. doi: 10.1136/vr.103593

83. Mulumba-Mfumu L, Goatley L, Saegerman C, Takamatsu HH, Dixon L. Immunization of African indigenous pigs with attenuated genotype I African swine fever virus OURT 88/3 induces protection against challenge with virulent strains of genotype I. Transbound Emerg Dis. (2016) 63:e323-7. doi: 10.1111/tbed.12303

84. Pérez-Núñez D, Sunwoo SY, Sánchez EG, Haley N, García-Belmonte R, Nogal $\mathrm{M}$, et al. Evaluation of a viral DNA-protein immunization strategy against African swine fever in domestic pigs. Vet Immunol Immunopathol. (2019) 208:34-43. doi: 10.1016/j.vetimm.2018.11.018

85. Niederwerder MC, Stoian AM, Rowland RR, Dritz SS, Petrovan V, Constance LA, et al. Infectious dose of African swine fever virus when consumed naturally in liquid or feed. Emerg Infect Dis. (2019) 25:891-7. doi: 10.3201/eid2505.181495

86. Manso-Ribeiro J, Nunes-Petisca J, Lopez-Frazao F, Sobral M. Vaccination against ASF. Bull Off Int Epizoot. (1963) 60:921-37.

87. Blome S, Gabriel C, Dietze K, Breithaupt A, Beer M. High virulence of African swine fever virus caucasus isolate in European wild boars of all ages. Emerg Infect Dis. (2012) 18:708. doi: 10.3201/eid1804.111813

88. Flanagan KL, Fink AL, Plebanski M, Klein SL. Sex and gender differences in the outcomes of vaccination over the life course. Ann Rev Cell Dev Biol. (2017) 33:577-99. doi: 10.1146/annurev-cellbio-100616-060718

89. Mujibi FD, Okoth E, Cheruiyot EK, Onzere C, Bishop RP, Fèvre EM, et al. Genetic diversity, breed composition and admixture of Kenyan domestic pigs. PLoS ONE. (2018) 13:e0190080. doi: 10.1371/journal.pone.0190080

Conflict of Interest: The authors declare that the research was conducted in the absence of any commercial or financial relationships that could be construed as a potential conflict of interest.

Copyright (c) 2020 Sang, Miller, Lokhandwala, Sangewar, Waghela, Bishop and Mwangi. This is an open-access article distributed under the terms of the Creative Commons Attribution License (CC BY). The use, distribution or reproduction in other forums is permitted, provided the original author(s) and the copyright owner(s) are credited and that the original publication in this journal is cited, in accordance with accepted academic practice. No use, distribution or reproduction is permitted which does not comply with these terms. 